\title{
Integration of informatics into education
}

\author{
Tom van Weert
}

School of Informatics

University of Nijmegen, The Netherlands

\begin{abstract}
Pushed by technology and pulled by society, Informatics and its applications are penetrating our lives at great speed, with considerable effect on work, education and leisure. Educational systems appear to lag behind technological developments. Demands from society, however, will force education to integrate information technology, and also Informatics as a science. Students will study in a multi-disciplinary team environment supported by integrated information technology. And a new Informatics Literacy, based on Discipline Integrated Informatics, will emerge.
\end{abstract}

Keywords: informatics as a study topic, integration, interdisciplinary, learner centred learning, literacy.

\section{INTRODUCTION}

Informatics or Computer Science is a branch of knowledge or study, especially concerned with establishing and systematising facts, principles, and methods, as by experiments and hypotheses. Its field of study, the design and realisation of programmable systems, is depicted in figure 1.

As Pure Informatics it is pursued simply oriented towards itself, without reference to applications. As Application Oriented Informatics it is pursued as a science oriented towards the design of applications. All of 


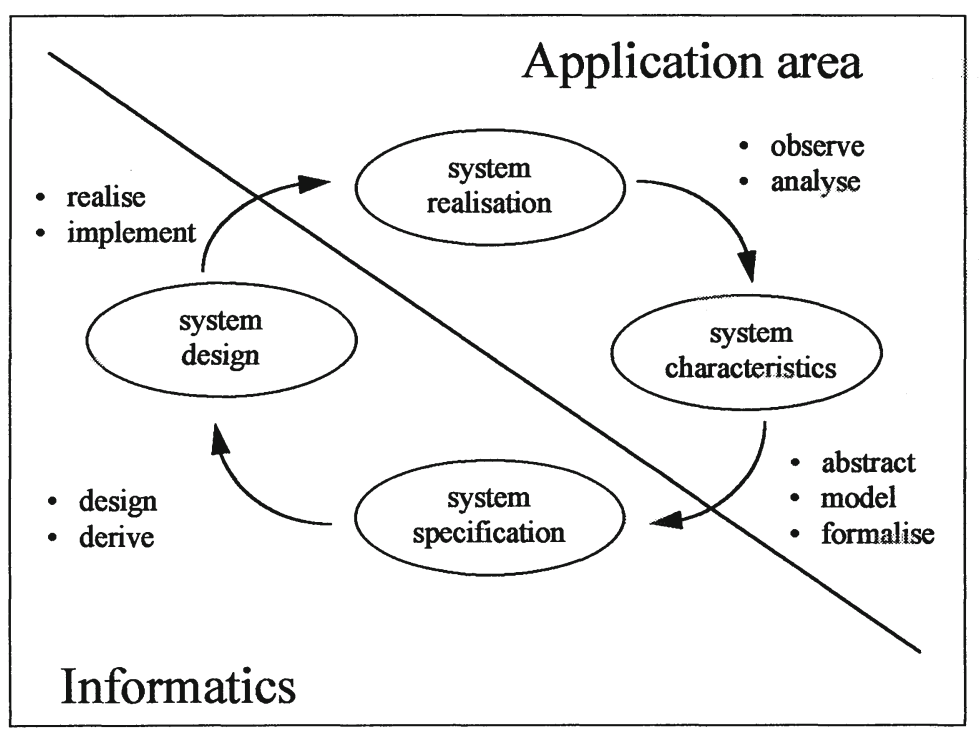

Figure 1: The design and realisation of programmable systems

such applications in society constitute a technology: Informatics Technology.

Sometimes the bond between informatics and another science or technology is so close that the two melt together into an "Informational Discipline" or an "Information Technology". The term Information Technology is often used to denote all the combinations of Informatics Technology and other, closely related technologies.

\section{THE INTEGRATION OF INFORMATICS INTO HIGHER EDUCATION}

In the curricula of higher education informatics is found in several forms: Pure Informatics, Application Oriented Informatics, and as part of Informational Disciplines into which informatics is integrated [1]. Learning to use applications of information technology is an integral part of study activities and is in general not considered to be part of an informatics study.

\section{Pure informatics}

Pure Informatics, the study in which informatics is studied purely for its own sake, encompasses such topics as automata theory, compiler construction, operating systems and complexity. 


\section{Application Oriented Informatics}

Informatics may also be studied with the aim of eventually building application systems, which are currently found in four broad, economically important areas. These are:

- Business Oriented Informatics deals with the development of information systems for applications in support of secondary business processes or, in the service industry, in support of primary business processes. It concerns itself with information needs of organisations.

- Technical Process Oriented Informatics deals with the development of technical systems for applications in the primary industrial processes, such as process control, telecommunications and computer aided design.

- Language Oriented Informatics deals with the development of language systems, language interfaces and with speech production and recognition.

- Cognitive Informatics deals with the development of knowledge systems and ergonomic human-computer interfaces.

These four types of informatics are each characterised by a special-purpose knowledge base and special purpose methods, techniques and technology. There is, however, a core of Application Oriented Informatics which is common to all four application areas; elements of this core are modelling, programming, design of data structures, software engineering and human-computer interfacing.

\section{Informatics integrated into "Informational Disciplines"}

Some scientific disciplines are strongly bound to informatics. This bond is forged by the use of principles, models, methods and techniques from informatics. The role of informatics in these disciplines is not just limited to the use of applications of informatics, but extends into the methodology of the discipline. The scientific questions addressed are within the domain of study of the discipline concerned, but their solution depends on scientific elements of informatics. Generally speaking, an informatics specification of possible answers to questions is developed, which then may run as a program on a computer. In other words, in an informational discipline, problems are analysed and solutions developed as dynamic models, using methods and techniques of Informatics; these models are then brought to life on a computer. In this way scientists are able to model the reality of their discipline in "dynamic symbols" [2], a virtual dynamic reality.

The study of an informational discipline in higher education typically consists of three parts - elements of study in the discipline itself, elements 
of Application Oriented Informatics and elements in which discipline and informatics are integrated. Application Oriented Informatics elements include modelling methods and techniques, design of data structures, programming methods and techniques, programming in a discipline specific high programming language, software engineering, and methods and techniques for human-computer interfacing. Shaw [3] mentions two examples of informational disciplines and refers to programmes at Carnegie-Mellon University, George Washington University, the University of Illinois, the University of Colorado in the U.S. and the University of Toronto in Canada. Other examples are also found at Nijmegen University (NL) in the areas of organisational and business science, the languages, psychology, the exact sciences and medicine [1]. At the IFIP working conference "Visualisation in scientific computing: Uses in university education" Weber [4] also presented an example in Chemistry.

\section{INFORMATICS AND ITS APPLICATIONS IN SOCIETY}

In industrial countries, society is rapidly changing from a supply driven society to a demand driven one. At the same time the organisational framework is changing from complex hierarchies for mass production to flexible, demand driven network organisations. In these organisations people work as responsible and capable individuals in multi-disciplinary teams instead of as anonymous parts in a Tayloristic hierarchy with its strong functional concentration. In the development of applications of Informatics in society, phases may be discerned of which the most recent offers a strong technology support to the new forms of organisation and work [5], [6].

\section{Automation: empowering the process}

In the first phase of development information technology was used to automate simple, standard "white collar" processes, such as business accounting.

\section{Information: empowering the individual}

The miniaturisation of computers lead to development of tools supporting the professional. Instead of being automated, the personal work processes were enhanced by this integrated support, thus empowering the individual to handle far more complicated and responsible tasks. 


\section{Communication: empowering the individual in the process}

Currently powerful personal computers are integrated in local area, wide area and global networks. We are at the beginning of developments which will bring us computers as personal, intelligent agents in communication networks interacting on our behalf with other such agents, and humans. The new organisational structures are in need of this type of technological support and draw heavily on these new technological developments, bringing their introduction and integration into society quickly forward.

\section{INFORMATICS AND ITS APPLICATIONS IN SECONDARY EDUCATION}

The uses of information technology and the study of the underlying scientific discipline Informatics in secondary education only to a certain extent have followed developments in society, regardless of whether the schools are situated in developed or developing countries.

\section{Automation: empowering the teaching process, learning about automation}

In the first development phase, automation, computers were used to automate clerical teaching tasks and an ill-fated effort was made to automate the teacher. In learning the subject of informatics or computer science dealt with the writing of simple programs in a computer language and with topics like the organisation of a computer centre.

\section{Information: computer literacy and applied informatics}

In the beginning of the second phase, students in schools learn to apply information technology in computer literacy classes. In a later stage, information technology is also used sparingly in other subject areas. In contrast to other organisations in society, schools are not able for the most part to empower individual students with a learning environment into which information technology is integrated. An overview over the problems may be found in [7]. The learning of informatics, that is learning of principles, methods and techniques of the science of informatics, mostly takes the form of learning to program in a higher programming language. An overview over developments here may be found in [8]. 


\section{Integrating information technology into education}

\section{Communication: Empowerment of the individual student in the learning process?}

In general developments in schools have become stuck in the second development phase. The integration of information technology into the learning process, thus empowering the individual student proves impossible because of traditional constraints of content and organisation. However, under pressure of the demands of a society entering the phase of communication, education will follow developments in society [6].

\section{DEMANDS ON EDUCATION}

\section{Other student competencies}

Developments in society bring forward a strong need for a workforce which is capable of high-level work in multi-disciplinary teams supported by integrated information technology [5], [6], [7]. This workforce has to cope with the increasing dynamic complexity of the working processes in society. For this they need higher order modelling capabilities for handling and interpreting dynamic models of reality; they need to be able to handle and interpret a virtual reality [2]. Secondary education will have to deal with these needs. It is now far less important to learn rote skills, such as reading, writing and arithmetic, then it is to learn higher intellectual skills, such as analysing, abstracting and modelling. And students have to learn to work in multi-disciplinary teams supported by integrated information technology [9]. That societies moving through constant technological change are in demand of people with high-level skills, higher than ever before, is also clearly stated by the Organisation for European Co-operation and Development [10]:

"In the manufacturing sector, requirements are shifting towards multi-skilled roles, teamwork and conceptual skills. In the service sector the focus is much the same, but with additional emphasis on customer and communication skills."

Conceptual and communication skills are central skills in an increasingly knowledge-intensive economy. Secondary education should allow students to develop such high-level skills.

\section{Modelling of dynamic processes}

To be able to cope with the increasingly complex dynamics of a world consisting of communicating processes, students need high-level modelling capabilities allowing them to build dynamic models of reality 
[2]. In higher education such needs are already addressed in informational disciplines. In these disciplines students learn to create dynamic models of reality which are implemented in special-purpose, conceptual "programming" languages which are specifically developed to model special micro-worlds of reality. This type of discipline integrated informatics modelling is expected to also penetrate into secondary education [9].

\section{Integration of IT competence}

Parents in society have experienced individual empowerment by information technology integrated into their working tasks. They will put a demand on education to use the same integrated technology to prepare their children for that society. This gives strong support to the integration of IT competence into the set of competencies of the educated person [7], of which competence another style of working and studying will an integral part.

\section{Multi-disciplinary education in teams}

More and more people in society will have to work as a responsible individual in a team tackling tasks which need a variety of skills to perform. Collaborative learning in multi-disciplinary teams may therefore be expected to be introduced into education. For developing countries this offers the extra advantage of maximising the use of scare resources. The organisation of education will need to change from a complex hierarchy suited to mass education to a flexible, student driven communication learning network. Technological developments will both support and demand this change [6].

\section{INTEGRATION OF INFORMATICS IN THE SECONDARY CURRICULUM}

Society is changing its structures and this change is supported by information technology. There is a demand on education to develop capabilities in the students which will allow them to cope in this changing society. This demand will lead to an integration of informatics into other disciplines or subject areas which integration is aimed at the development of high level modelling skills. Demands from society will also lead to real integration of information technology into the learning process and a change in content and organisation. 


\section{Integrating information technology into education}

\section{Discipline integrated informatics: a new literacy}

Ershov in his keynote address at the IFIP World Conference on Computers in Education in 1981 [11] pointed at the emergence of a new literacy as compared with traditional literacy (reading and writing); in his view programming was the key feature of this literacy. This metaphor has been taken further [2] to describe a new literacy emerging which is based on the capability to construct executable symbols (programming in a generalised sense) reflecting complex, dynamic, conceptual models of reality. Interpretation of such models will allow people to cope with a dynamically changing, complex reality of interacting processes.

This new literacy is built on application oriented informatics and forms, as discipline integrated informatics, part of informational disciplines. Just as in higher education, these informational disciplines will develop in secondary education within the usual subject areas, allowing students to build up higher order modelling skills in that area. Discipline integrated informatics will be the new "informatics for all", aimed at development and interpretation of dynamic models. This "informatics for all" will be not only an introductory course, as these skills will have to be mastered by all the students in order to prepare them for society. Some indication of what is to come may be found in the UNESCO Curriculum for Schools [12], where a module on applications of modelling is introduced based on discipline integrated "Subject Oriented Programming" with tools, such as a spreadsheet or a computer algebra system.

\section{Integrative use of IT in multi-disciplinary teams}

Just as in society, students will learn to use information technology in an integrative way, empowering them as individuals in the context of multi-disciplinary teams. The integrated use of information technology will force subjects to change in content, just as this use changes the content of work in business and industry. A clear example may be found in mathematics where, after the changes brought about by the hand-held calculator, the use of computer algebra tools like Maple, Derive or Mathematica now deeply influences the work of professionals. This influence will inevitably lead to changes in the content of mathematics as a subject in secondary education.

\section{Application oriented informatics}

Application oriented informatics is part of the new literacy in secondary education, aimed at all students. In the teaching of application oriented informatics there will be a move away from learning to program in 
traditional programming languages. Instead, students in secondary education will learn to program in conceptual languages which model "micro-worlds" of interest to the students or to a particular discipline. The study of application oriented informatics will include: modelling methods and techniques, the design of conceptual data structures and program design in high level, conceptual programming languages.

"Informatics for a few" will also be offered in preparation for particular jobs or particular further studies. In informatics for a few some more advanced topics such as software engineering and design of human-computer interfaces will be included.

\section{CONCLUSION}

Developments in secondary education with respect to informatics and its applications may be characterised according to the phase of technological development. With each phase in development (automation, information or communication) the integration of informatics and its applications in education is further developed.

From the computer programming and social aspects of computing of the automation phase emerged computer literacy, ad-hoc use of application tools in subjects, and some elements from application oriented informatics, i.e. modelling and general purpose programming, of the information phase. By the time of the communication phase, discipline integrated informatics will emerge as a new literacy and there will also be information technology literacy, integrated in the subject areas. The content of subject areas will change, just as educational organisation and the way students learn. There will also be application oriented informatics as an elective, dealing with modelling, conceptual programming and data structures, human-computer interfacing and software engineering.

\section{REFERENCES}

1. van Weert, T. J. (1992) Application Oriented Informatics and Informational Disciplines: A symbiosis bridging the gap, in: R. Aiken (ed.), Information Processing 92 (II). Elsevier Science Publishers B. V., Amsterdam, 144-150.

2. van Weert, T. J. (1988) Literacy in the Information Age, in: Sendov, Bl. $\&$ Stanchev, I. (eds.), Children in the Information Age, Pergamon Press, Oxford, 109-122. 
3. Shaw, M. (1991) Informatics for a new century: computing education for the 1990's, special issue of Education \& Computing, 7 9-17.

4. Weber, J. (1994) Visualising microscopic molecular worlds in chemical education, in: Franklin, S. \& Stubberud, A. (eds.), Visualisation in scientific computing: Uses in university education, Elsevier Science Publishers B. V., Amsterdam (in print).

5. Hammer M. \& Champy, J. (1993) Re-engineering the corporation. Nicholas Brealy Publishing, London, 83 - 101.

6. van Weert, T. J. (1992) Informatics and the organization of education, in: Samways, B. \& van Weert, T. J. (eds.), The impacts of informatics on the organization of education. Elsevier Science Publishers B. V., Amsterdam, 15-24.

7. van Weert, T. J. (1994) Education and computers; Who is in control?, in: xxxxxx Information Processing 94, Elsevier Science Publishers B. V., Amsterdam (in preparation).

8. Taylor, H. G., Aiken, R. M. \& van Weert, T. J. (1991) Informatics education in secondary schools, IFIP Working Group 3.1, Guidelines for Good Practice. IFIP, Geneva.

9. Ruíz i Tarrago, F. R. (1993) Integration of Information Technology into Secondary Education: Main issues and perspectives, in:

van Weert, T. J. (ed.), IFIP Working Group 3.1, Guidelines for Good Practice. IFIP, Geneva, 7-15.

10. OECD (1988) New technologies in the 1990's - A socio-economic strategy, OECD, Paris.

11. Ershov, A. P. (1981) Programming: the second literacy, in:

Lewis, R. \& Tagg, D.(eds.), Computers and Education, (North-Holland Publ. Co., Amsterdam, p. 1-7.

12. J. D. Tinsley \& T. J. van Weert, eds., (1994) Informatics for secondary education, A curriculum for schools. UNESCO, Paris. 


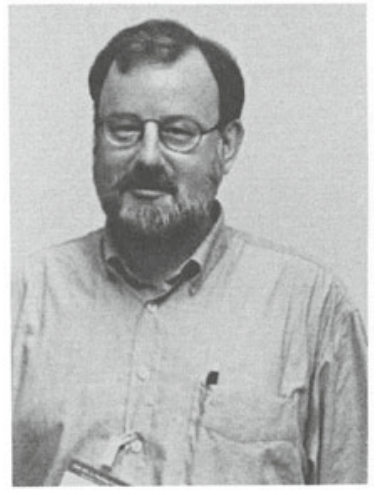

Tom van Weert is dean of the undergraduate School of Informatics (Computer Science) of the Faculty of Mathematics and Informatics of the University of Nijmegen. He teaches management of large software projects to students developing real software applications in multi-disciplinary teams. Previously he worked in secondary teacher education, teaching mathematics and informatics, and prior to that as a computer system engineer. $\mathrm{He}$ has been active within IFIP Working Groups 3.1 on secondary education, 3.2 on university education and 3.5 on vocational education. 